\title{
ĐÁNH GIÁ NGUY CƠ RỦI RO DO HẠN HÁN PHỤC VỤ PHÁT TRIỂN KINH TẾ XÃ HộI CHO KHU VỰC TÂY NGUYÊN
}

\author{
Vũ Đức Long ${ }^{1}$, Nguyễn Thị Thu Trang ${ }^{2}$
}

Tóm tắt: Bài báo nghiên cưu đánh giá mức độ rủi ro do thiên tai hạn hán gây ra cho khu vực Tây Nguyên sủ dụng phuơng pháp của IPCC, coi rủi ro là tổng hợp của 3 thành phần nguy co hiếm họa, tính phơ bày và tính dễ bị tổn thuoong. Kết quả tính toán cho thấy có $44 \%$ số huyện ở khu vực Tây Nguyên có mức độ rủi ro được quyết định bởi thành phần hiểm họa, có 37\% số huyện có mức độ rủi ro được quyết định bởi thành phần mức độ phơi bày và $19 \%$ số huyện có mức độ rủi ro được quyết định bởi thành phần tính dễ bị tổn thuoong. Đắk Lắk là tỉnh có số huyện có nguy co rủi ro do hạn hán cao nhất chiếm 73\%, tiếp theo là Gia Lai chiếm 59\%, Kon Tum có nguy co rủi ro thấp nhất với $80 \%$ số huyện có nguy co rủi ro ở mức thấp. Các kết quả được thể hiện trên các bản đồ phân vùng nguy co rủi ro với các cấp độ tù rất thấp đến thấp, trung bình, cao và rất cao, trực quan dễ sư dụng. Kết quả nghiên cứu có thể sử dụng trong công tác quy hoạch, định huớng phát triển kinh tế xã hội ở khu vực Tây Nguyên và phuc vu công tác cảnh báo cấp độ rủi ro do hạn hán tại Quyết định số 44/2014/QĐ-TTg ngày 15 tháng 8 năm 2014 của Thủ tuớng Chính phủ.

Từ khóa: Rủi ro, hạn hán, Tây Nguyên.

Ban Biên tập nhận bài: 12/2/2020 Ngày phản biện xong: 20/3/2020 Ngày đăng bài: 25/3/2020

\section{Mở đầu}

Khu vực Tây Nguyên là vùng đất gồm có 5 tỉnh xếp theo thứ tự vị trí địa lý từ Bắc vào Nam là: Kon Tum, Gia Lai, Đắk Lắk, Đắk Nông và Lâm Đồng. Khu vực Tây Nguyên có diện tích khá rộng lớn là $54.4 \mathrm{~km}^{2}$, là một trong những vùng thường xuyên bị khô hạn ở nước ta, hệ thống sông suối tuy khá phát triển nhưng do địa hình dốc, chiều dài sông ngắn nên vào mùa mưa thường chảy xiết, mùa khô thì hầu như khô kiệt, do đó nguồn nước mặt khá hạn chế. Gần đây nhất dưới tác động của hiện tượng El Nino trong năm 2015-2016, hạn hán đã diễn ra khốc liệt nhất trong 15 năm qua ở khu vực Tây Nguyên, lượng nước trên các ao hồ, công trình thủy lợi rơi vào tình trạng cạn kiệt và gây thiệt hại lớn cho ngành nông nghiệp. Theo báo cáo của Ban Chỉ đạo Trung ương về phòng, chống thiên tai, khu vực Tây Nguyên đã có gần 175.000 ha cây trồng bị ảnh hưởng hạn hán (Kon Tum 3.800 ha, Gia Lai 46.000 ha, Đắk Lắk 80.000 ha, Đắk Nông 23.000 ha, Lâm Đồng 31.300 ha); Tổng kinh phí thiệt hại toàn vùng lên đến gần 4.000 tỷ đồng (Kon Tum 160 tỷ, Gia Lai 200 tỷ, Đắk Lắk 2.200 tỷ, Đắk Nông 1.200 tỷ và Lâm Đồng 180 tỷ). Nguyên nhân chính gây ra hạn hán là sự thay đổi của thời tiết dưới tác động biến đổi khí hậu toàn cầu và tác động của con người đã làm thiên tai hạn hán ở khu vực Tây Nguyên ngày càng trở nên gay gắt hơn.

Để tạo cơ sở đánh giá rủi ro do thiên tai hạn hán gây ra cho các địa phương, căn cứ Luật phòng, chống thiên tai, Thủ tướng Chính phủ đã ban hành quyết định số 44/2014/QĐ-TTG Quy định chi tiết về cấp độ rủi ro thiên tai, trong chương II, điều 7 có quy định về cấp độ rủi ro thiên tai do hạn hán. Việc phân cấp cấp độ rủi ro do hạn hán chỉ dựa trên các thông số của hai loại hạn là hạn khí tượng và hạn thủy văn và căn cứ vào cường độ để phân thành 4 cấp mà chưa tính đến những tác động do hạn hán gây ra cho kinh tế, xã hội.

Các phương pháp đánh giá rủi ro ngày càng phát triển đa dạng, có thể nhóm lại theo hai

${ }^{1}$ Trung tâm Dư báo khi tương thủy văn quốc gia

${ }^{2} V u$ Quản lý Dư báo khí tuợng thủy văn

Email:longkttv@gmail.com 


\section{BÀI BÁO KHOA HỌC}

hướng đánh giá trực tiếp (mang tính định tính), gián tiếp (mang tính định lượng-thông qua bộ chỉ số). Hiện nay phổ biến trên thế giới và Việt Nam là các phương pháp điều tra xã hội học, phương pháp tích hợp bản đồ, phương pháp chỉ số. Việc thu thập các thông tin các yếu tố cấu thành nên rủi ro như nguy cơ hiểm họa, tính dễ bị tổn thương, tính phơi bày thường không đồng nhất về thứ nguyên, các nhà khoa học đề xuất tính toán dưới các chỉ số đặc trưng được chuẩn hóa phương pháp này phản ánh được mức độ đóng góp của các yếu tố thành phần cũng như tác động của từng yếu tố đến mục tiêu cần đánh giá rủi ro.

Trong bài báo này chúng tôi giới thiệu một số kết quả đánh giá nguy cơ rủi ro do thiên tai hạn hán dựa theo phương pháp của IPCC trong đó thành phần hiểm họa dựa trên các tiêu chí về thiếu hụt mưa và nguồn nước của Quyết định 44/2014/QĐ-TTg của Thủ tướng Chính phủ và bổ sung các thành phần về mức độ phơi bày và tính dễ bị tổn thương để làm rõ mức độ nguy cơ bị ảnh hưởng chi tiết tới các huyện thuộc khu vực Tây Nguyên.

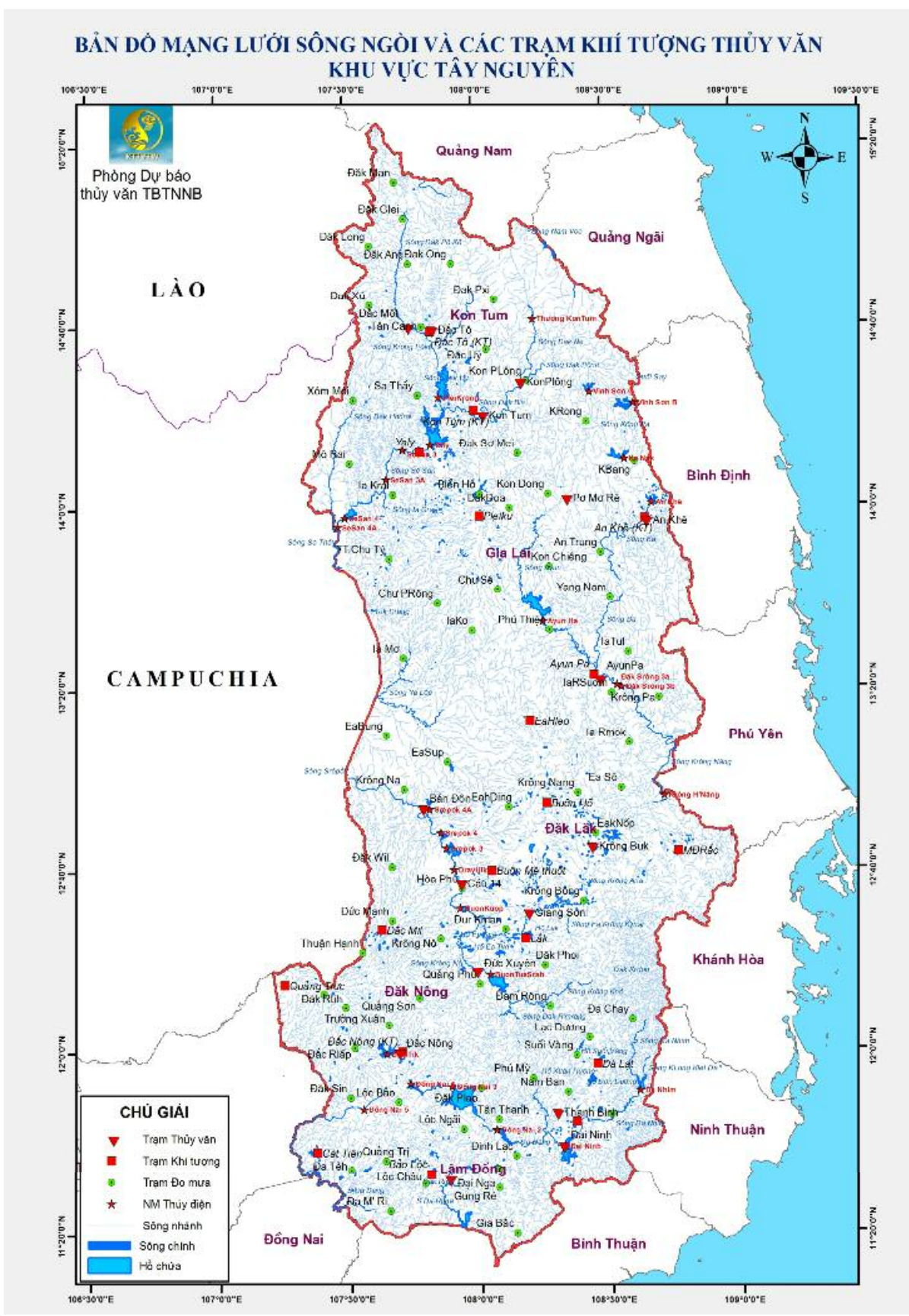

Hình 1. Bản đồ khu vục Tây Nguyên 


\section{Phương pháp nghiên cứu}

\subsection{Số liệu sử dụng}

- Số liệu khí tượng thủy văn bao gồm: 39 trạm đo mưa và 15 trạm thủy văn với chuỗi số liệu từ năm 1980 đến 2018.

- Số liệu điều tra xã hội học của 5 tỉnh Tây Nguyên: 1500 phiếu điều tra được thiết kế dưới dạng các bảng hỏi, chia 2 loại cho cán bộ địa phương và cho người dân với các thông tin về kinh tế, xã hội, môi trường, khả năng tiếp nhận các thông tin dự báo, cảnh báo hạn hán... những bảng hỏi không đáp ứng được yêu cầu của cuộc điều tra sẽ bị loại bỏ trước khi nhập số liệu. Dựa vào các phương án trả lời, các câu hỏi định tính sẽ được định lượng hóa bằng cách gán giá trị từ 1 đến 5 , tương ứng từ thấp đến cao.

\section{2. Đánh giá nguy cơ rủi ro do thiên tai hạn} hán

Theo IPCC, nguy cơ rủi ro do thiên tai hạn hán được xác định dựa trên nguy cơ xuất hiện thiên tai (nguy cơ hiểm họa), sự hiện diện của con người, cơ sở hạ tầng, kinh tế, xã hội có thể bị ảnh hưởng xấu (tính phơi bày) và khả năng dễ bị tổn thương trước thiên tai (tính dễ bị tổn thương) $[3,4]$.

Quy trình tính toán xác định nguy cơ rủi ro theo phương pháp chỉ số gồm 6 bước:

Bước 1: Thu thập và xử lý số liệu

Bước 2: Xác định các tiêu chí, các thành phần

Bước 3: Chuẩn hóa các chỉ số thành phần

- Nếu quan hệ giữa thành phần phụ và chỉ số rủi ro là đồng biến, công thức chuẩn hóa như sau:

$$
\left[X_{k, i, j i}\right]=\frac{X_{k, i, j i}-\operatorname{MinX} X_{k, i, j i}}{\operatorname{Max}_{k, i, j i}-\operatorname{Min} X_{k, i, j i}}
$$

- Nếu quan hệ giữa thành phần phụ và chỉ số rủi ro là nghịch biến, công thức chuẩn hóa như sau:

$$
\left[X_{k, i, j i}\right]=\frac{\operatorname{Max} X_{k, i, j i}-X_{k, i, j i}}{\operatorname{Max} X_{k, i, j i}-\operatorname{Min} X_{k, i, j i}}
$$

Trong đó $\left[X_{k, i, j i}\right]$ là giá trị chuẩn hóa; $X_{k, i, j i}$ là giá trị ban đầu của thành phần phụ $\mathrm{j}_{\mathrm{i}}$ của thành phần chính $\mathrm{i}$ của đơn vị hành chính $\mathrm{k}$; $\operatorname{Max} X_{\mathrm{k}, \mathrm{ijj}}$ và $\operatorname{Min} X_{\mathrm{k}, \mathrm{i}, \mathrm{i} i}$ lần lượt là giá trị lớn nhất và nhỏ nhất của thành phần phụ ji trong toàn bộ các đơn vị hành chính của vùng nghiên cứu.
Bước 4: Xác định trọng số của các thành phần sư dụng phưong pháp tính trọng số bất cân bằng do Iyengar \& Sudarshan đề xuất (1982).

Trọng số của từng thành phần phụ $\left[\mathrm{X}_{\mathrm{k}, \mathrm{i}, \mathrm{ji}}\right]$ được xác định bởi công thức:

$$
w_{k, i, j i}=\frac{c}{\sqrt{\operatorname{Var}\left(\left[X_{k, i, j i}\right]\right)}}
$$

Trong đó $\mathrm{w}_{\mathrm{k}, \mathrm{iji}}$ là trọng số của thành phần phụ $\mathrm{j}_{\mathrm{i}}$ của thành phần chính $\mathrm{i}$ của đơn vị hành chính $\mathrm{k}$ của thành phần $\mathrm{H} / \mathrm{E} / \mathrm{V}$ và tổng trọng số của $\mathrm{W}_{\mathrm{k}, \mathrm{i}, \mathrm{j}} \mathrm{i}$ bằng $1 ; \mathrm{c}$ là hằng số được tính như sau:

$$
c=\left[\sum_{j i=1}^{n i} \frac{1}{\sqrt{\operatorname{Var}\left(\left[X_{k, i, j i}\right]\right)}}\right]^{-1}
$$

Trong đó $\mathrm{n}_{\mathrm{i}}$ là số thành phần phụ của thành phần chính i.

- $\operatorname{Var}_{(\mathrm{xj})}$ là phương sai của thành phần phụ $\mathrm{j}_{\mathrm{i}}$ trên tất cả các đơn vị hành chính được xác định bởi công thức:

$$
\operatorname{Var}\left(\left[X_{k, i, j i}\right]\right)=\sum_{k=1}^{P} \frac{\left(\left[X_{k, i, j i}\right]-\overline{\left[X_{k, i, j i}\right]}\right)^{2}}{(P-1)}
$$

$\mathrm{P}$ là số đơn vị hành chính của vùng nghiên cứu; $\overline{\left[X_{k, i, j i}\right]}$ là giá trị trung bình của thành phần phụ $\mathrm{j}_{\mathrm{i}}$ của thành phần chính $\mathrm{i}$.

$$
\overline{\left[X_{k, i, j i}\right]}=\frac{1}{P} \sum_{k=1}^{P}\left[X_{k, i, j i}\right]
$$

Bước 5: Tính toán chỉ số rủi ro theo công thíc:

$$
\mathrm{R}=\mathrm{H} \times \mathrm{E} \times \mathrm{V}
$$

Trong đó: $\mathrm{H}$ - Hiểm họa $(\mathrm{H})$; E - Mức độ phơi bày trước hiểm họa; $\mathrm{V}$ - Tính dễ bị tổn thương

$$
\mathrm{V}=\mathrm{S} \times \mathrm{W}_{\mathrm{S}}+\mathrm{AC} \times \mathrm{W}_{\mathrm{AC}}
$$

Trong đó $\mathrm{W}_{\mathrm{s}}$ là trọng số của thành phần nhạy cảm $(\mathrm{S})$ và $\mathrm{W}_{\mathrm{AC}}$ là trọng số của thành phần Khả năng thích ứng $(\mathrm{AC})$.

Bước 6: Đánh giá rủi ro hạn hạn hán

Theo IPCC-AR5 để đánh giá các thành phần của rủi ro, áp dụng cách phân cấp theo các ngưỡng tương ứng với các giá trị được chuyển đổi theo cấp độ tác động, gán ý nghĩa cho các giá trị ngưỡng từ rất thấp đến rất cao. Cụ thể nếu giả thiết phân bố của $\mathrm{R}$ là phân bố đều trong khoảng $0-1$, các giá trị chia thành 5 khoảng ứng với với 5 cấp độ rủi ro (rất thấp, thấp, trung bình, cao và rất cao), mỗi khoảng có cùng xác suất $20 \%$. 
Bảng 1. Co sở phân cấp cấp độ rủi ro

\begin{tabular}{ccc}
\hline TT & Giá trị chuẩn hóa & Cấp độ rủi ro \\
\hline 1 & $0-0,2$ & Rất thấp \\
2 & $0,2-0,4$ & Thấp \\
3 & $0,4-0,6$ & Trung bình \\
4 & $0,6-0,8$ & Cao \\
5 & $0,8-1,0$ & Rất cao \\
\hline
\end{tabular}

Để tổng hợp các thành phần rủi ro bài báo sử dụng ma trận đánh giá kết hợp ba thành phần nguy cơ hiểm họa, tính phơi bày và tính dễ bị tổn thương.

\section{Một số kết quả và thảo luận}

\section{1. Đánh giá nguy co hiểm họa}

Để đánh giá nguy cơ hiểm họa do hạn hán gây ra, bài báo dựa trên các tiêu chí thiếu hụt mưa và thiếu hụt dòng chảy. Các chỉ tiêu để đánh giá thiếu hụt mưa và dòng chảy theo Quyết định 44/2014/QĐ-TTg của Thủ tướng Chính phủ quy định chi tiết về dự báo, cảnh báo và truyền tin thiên tai cho hạn hán [1]. Áp dụng công thức tính chỉ số hiểm họa, kết quả như sau.

Đối với nguy cơ thiếu hụt lượng mưa trên $50 \%$, vùng xảy ra nặng nhất ở phía tây bắc khu vực Tây Nguyên tập trung chủ yếu ở các tỉnh
Kon Tum, Gia Lai và Đắk Lắk trong đó Đắk Lắk có nguy cơ cao hơn, giảm mạnh ở phía nam khu vực Tây Nguyên thuộc các tỉnh Đắk Nông và Lâm Đồng.

Đối với nguy cơ thiếu hụt nguồn nước trên $20 \%$ và $50 \%$, vùng có nguy cơ cao nhất ở tỉnh Đắk Lắk sau đó giảm dần về phía bắc và phía nam, trong đó phía Tây bắc thuộc khu vực tỉnh Kon Tum, nguy cơ thiếu hụt nguồn nước thấp hơn các nơi khác trong khu vực Tây Nguyên.

Đối với nguy cơ xảy ra thiếu hụt nguồn nước trên $70 \%$, vùng có nguy cơ cao nhất ở các huyện Krông păk, Eaka, Krong Năng và thị xã Buôn Hồ của tỉnh Đắk Lắk, tiếp theo là vùng An Khê, Đắk Pơ của Gia Lai sau đó giảm dần về phía bắc, phía tây và phía nam.

Bảng 2. Kết quả tính toán trọng số hiểm họa khu vực Tây Nguyên

\begin{tabular}{ccc}
\hline Thành phần & Tiêu chí & Trọng số \\
\hline \multirow{2}{*}{ Nguy cơ hiểm họa } & Thiếu hụt nguồn nước & 0.539 \\
& Thiếu hụt lượng mưa & 0.461 \\
\hline
\end{tabular}

Bảng 3. Kết quả tính toán chỉ số hiểm họa khu vực Tây Nguyên

\begin{tabular}{lccc}
\hline \multicolumn{1}{c}{ Tỉnh } & Thiếu hụt mưa & $\begin{array}{c}\text { Chỉ số thiếu hụt } \\
\text { nguồn nước }\end{array}$ & $\begin{array}{c}\text { Chỉ số nguy cơ } \\
\text { hiểm họa }\end{array}$ \\
\hline Kon Tum & 0.47 & 0.16 & 0.34 \\
Gia Lai & 0.30 & 0.51 & 0.40 \\
Đắk Lắk & 0.34 & 0.68 & 0.50 \\
Đắk Nông & 0.36 & 0.34 & 0.35 \\
Lâm Đồng & 0.39 & 0.45 & 0.42 \\
\hline
\end{tabular}

Một số nơi có nguy cơ hiểm họa do hạn hán ở mức rất cao tập trung ở các tỉnh Kon Tum và Đắk Lắk như các huyện Đắk Glei, Đắk Pơ, Sa Thầy tỉnh Kon Tum, huyện Chư Pưh, Chư Sê tỉnh Gia Lai, huyện Ea Súp, Krong Buk, Krông Năng, Cư Mga, Buôn Hồ, Krong Păk, EaKar, Lắk tỉnh Đắk Lắk.

Những nơi có nguy cơ hiểm họa do hạn hán ở mức rất thấp tập trung ở các tỉnh Gia Lai, Kon Tum và Lâm Đồng như các huyện Chư Păk, Phú Thiện tỉnh Gia Lai, huyện Ngọc Hồi, Đăk Tô, Đắk Hà, Kon Rẫy, Kon Tum tỉnh Kon Tum, huyện Buôn Đôn tỉnh Đắk Lắk, huyện Di linh, Bảo Lộc, Đức Trọng và thành phố Đà Lạt tỉnh Lâm Đồng 
BÀI BÁO KHOA HỌC

Bảng 4. Kết quả tính toán \% số huyện có nguy co hiểm họa do hạn hán theo các mức

\begin{tabular}{cccccc}
\hline Rủi ro & Rất cao & Cao & Trung bình & Thấp & Rất thấp \\
\hline Kon Tum & 20.0 & & 10.0 & 20.0 & 50.0 \\
Gia Lai & 17.6 & 23.5 & 23.5 & 29.4 & 5.9 \\
Đắk Lắk & 53.3 & 33.3 & 6.7 & & 6.7 \\
Đắk Nông & & 12.5 & 50.0 & 37.5 & \\
Lâm Đồng & & 41.7 & 8.3 & 16.7 & 33.3 \\
\hline
\end{tabular}

Tỉnh Đắk Lắk có $87 \%$ số huyện có nguy cơ xảy ra hạn hán cao, số huyện nguy cơ thấp chiếm $7 \%$ và $6 \%$ số huyện có nguy cơ trung bình; tỉnh Lâm Đồng có $42 \%$ số huyện có nguy cơ cao, nguy cơ thấp chiếm $50 \%$ và $8 \%$ số huyện có nguy cơ trung bình, tỉnh Gia Lai có $41 \%$ số huyện có nguy cơ cao, nguy cơ thấp chiếm 35\% và $24 \%$ số huyện có nguy cơ trung bình; tỉnh Kon Tum có $20 \%$ số huyện có nguy cơ cao, nguy cơ thấp chiếm $70 \%$ và $10 \%$ số huyện có nguy cơ trung bình; tỉnh Đắk Nông có $12 \%$ số huyện có nguy cơ cao, nguy cơ thấp chiếm $38 \%$ và $50 \%$ số huyện có nguy cơ trung bình.

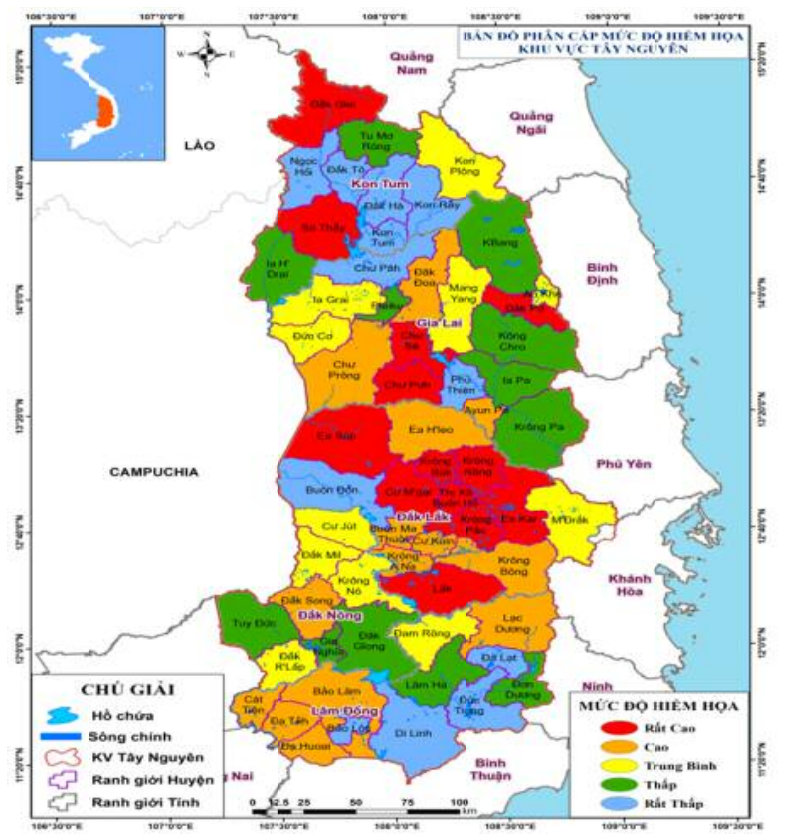

Hình 2. Bản đồ nguy co hiểm họa do hạn hán gây ra cho khu vực Tây Nguyên

\section{2. Đánh giá mức độ phơi bày}

Theo IPCC, mức độ phơi bày có liên quan đến các yếu tố phơi nhiễm cụ thể (hoặc các yếu tố có nguy cơ) như con người, cơ sở hạ tầng, hệ sinh thái, có thể được biểu thị bằng số lượng, mật độ ... của các yếu tố có nguy cơ [2,3,4]. Mức độ phơi bày trước hiểm họa do hạn hán gây ra thể hiện qua các tiêu chí về sử dụng đất và mật độ dân số trong vùng chịu ảnh hưởng bởi hạn hán. Áp dụng công thức tính chỉ số hiểm họa, kết quả như trong bảng 5 .

Với tiêu chí sử dụng đất, nơi mức độ phơi bày cao là các huyện Cư M'Ga, Krông Păk, Krong Ana, thành phố Buôn Mê Thuột, EaHleo, Krong Buk, Krong năng, CưKuin (Đắk Lắk), huyện Đăk Song, Đăk Mil (Đắk Nông), huyện Đắk Đoa, Chư Păh, Chư Pưh, IaGrai, Đức Cơ, thành phố Pleicu
(Gia Lai), huyện Lâm Hà, thành phố Bảo Lộc (Lâm Đồng), thành phố Kon tum tỉnh Kon Tum; nơi có nơi mức độ phơi bày thấp nhất là huyện Lạc Dương của tỉnh Lâm Đồng.

Với tiêu chí dân số, nơi có nơi mức độ phơi bày cao nhất là huyện Krông Năng tỉnh Đắk Lắk, thành phố Bảo Lộc, Đà Lạt tỉnh Lâm Đồng.

Một số nơi có mức độ phơi bày tổng hợp cao trước thiên tai hạn hán như thành phố Pleiku tỉnh Gia Lai, Đà Lạt tỉnh Lâm Đồng, huyện Krông Buk, Krông Păk, thị xã Buôn Hồ tỉnh Đắk Lắk. Nơi có mức độ phơi bày thấp nhất là huyện Lạc Dương của tỉnh Lâm Đồng, đây là huyện có dân số không cao, diện tích rừng lớn, diện tích mặt nước cũng tương đối cao nên mức độ phơi bày trước thiên tai hạn hán sẽ thấp. 


\section{BÀI BÁO KHOA HỌC}

Bảng 5. Trọng số các chỉ số mức độ phơi bày cho 5 tỉnh thuộc khu vục Tây Nguyên

\begin{tabular}{ccc}
\hline Thành phần & Tiêu chí & Trọng số \\
\hline \multirow{2}{*}{ Tính phơi bày } & Sử dụng đất & 0.593 \\
& Dân số & 0.407 \\
\hline
\end{tabular}

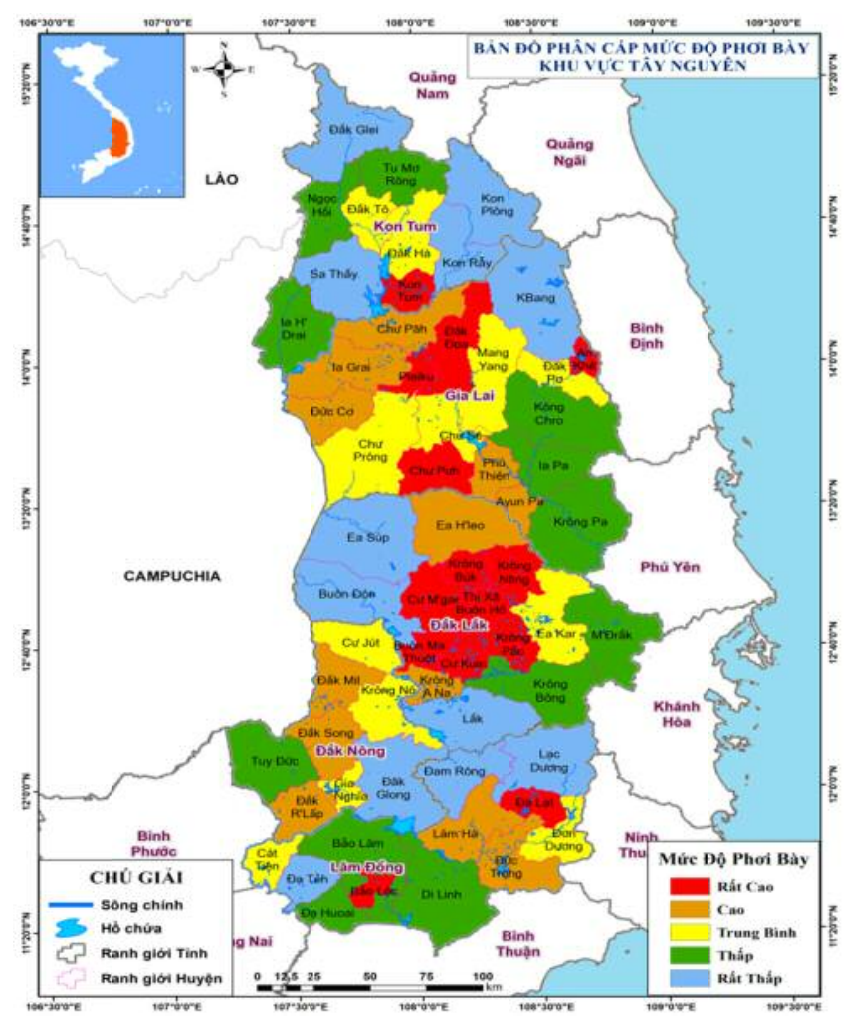

Hình 3. Bản đồ phân cấp mức độ phơi bày trước thiên tai hạn hán ở khu vực Tây Nguyên

Bảng 6. Chỉ số mức độ phơi bày trung bình các tỉnh khu vục Tây Nguyên

\begin{tabular}{crrrrr}
\hline Tỉnh & Số dân & $\begin{array}{c}\text { Diện tích đất } \\
\text { sản xuất } \\
\text { nông nghiệp } \\
\text { (ha) }\end{array}$ & $\begin{array}{c}\text { Diện tích đất } \\
\text { lâm nghiệp } \\
\text { (ha) }\end{array}$ & $\begin{array}{c}\text { Diện tích } \\
\text { mặt nước } \\
\text { (ha) }\end{array}$ & Chỉ số phơi bày \\
\hline Kon tum & 508,502 & 214,856 & 641,056 & $10,258.29$ & 0.301 \\
Gia Lai & $1,756,645$ & 801,727 & 588,648 & $27,560.79$ & 0.407 \\
Đắk Lắk & $1,874,459$ & 627,126 & 528,643 & 23,233 & 0.422 \\
Đắk Nông & 609,595 & 360,153 & 235,556 & 18,234 & 0.359 \\
Lâm Đồng & $1,270,014$ & 539,792 & 27,594 & 21,298 & 0.365 \\
\hline
\end{tabular}

* Số liệu điều tra đề tài TNMT.2017.05.21

Bảng 7. Kết quả tính toán \% số huyện có mức độ phơi bày trước thiên tai hạn hán theo các mức

\begin{tabular}{lccccc}
\hline Rủi ro & Rất cao & Cao & Trung bình & Thấp & Rất thấp \\
\hline Kon Tum & 10.0 & & 20.0 & 30.0 & 40.0 \\
Gia Lai & 23.5 & 29.4 & 23.5 & 17.6 & 5.9 \\
Đắk Lắk & 41.2 & 11.8 & 17.6 & 11.8 & 17.6 \\
Đắk Nông & & 37.5 & 37.5 & 12.5 & 12.5 \\
Lâm Đồng & 16.7 & 16.7 & 16.7 & 25.0 & 25.0 \\
\hline
\end{tabular}


Số huyện có mức độ phơi bày trước nguy cơ hạn hán ở mức cao của tỉnh Đắk Lắk chiếm $60 \%$, mức thấp chiếm $30 \%$ và $20 \%$ số huyện ở mức trung bình; số huyện có mức độ phơi bày ở mức cao của tỉnh Gia Lai chiếm $53 \%$, mức thấp chiếm $41 \%$ và $6 \%$ số huyện ở mức trung bình; tỉnh Đắk Nông có $38 \%$ số huyện ở mức cao, $25 \%$ số huyện ở mức thấp và $37 \%$ số huyện ở mức trung bình; tỉnh Lâm Đồng có 33\% số huyện ở mức cao, $50 \%$ số huyện ở mức thấp và $18 \%$ số huyện có ở mức trung bình; tỉnh Kon Tum có $10 \%$ số huyện ở mức cao, $70 \%$ số huyện có nguy cơ ở mức thấp và $20 \%$ số huyện ở mức trung bình.

\section{3. Đánh giá tính dễ bị tổn thương}

Theo IPCC $[2,3,4]$, tính dễ bị tổn thương bao gồm sự nhạy cảm, thiếu khả năng ứng phó và thích nghi của mỗi khu vực khi thiên tai khi xảy ra. Các tiêu chí đánh giá tính nhạy trước hiểm họa do hạn hán bao gồm: Thông tin về dân số, sinh kế, thông tin về cảnh báo dự báo, môi trường, hiện trạng tự nhiên của rừng và nước ngầm trong khu vực xảy ra hạn hán.

Kết quả tính toán cho thấy những nơi có chỉ số tính nhạy ở mức rất cao đều là những nơi tập trung dân số cao, là trung tâm phát triển kinh tế xã hội và du lịch dịch vụ của vùng như thành phố Kon Tum, huyện Sa Thầy, KonPlong tỉnh Kon Tum, huyện Bản Đôn, Lắk, Krông Buk tỉnh Đắk Lắk, huyện Chư Păk, IaGrai, Mang Yang, Chư Sê, thành phố Pleicu tỉnh Gia Lai, huyện Đăk Mil tỉnh Đắk Nông, các huyện có tính nhạy ở mức rất thấp như Đắk Glei, Tu Mơ Rông, Đắk Tô, Đắk Hà, Ia Hrai tỉnh Kon Tum, huyện Krông Năng tỉnh Đắk Lắk, huyện Tuy Đức, Đắk R'Lấp, Đắk Glong tỉnh Đắk Nông, Đam Rông, Lạc Dương, Đạ Terh tỉnh Lâm Đồng.

Những huyện có chỉ số năng lực đối phó và thích ứng với thiên tai hạn hán ở mức rất cao như Đắk Glei (tỉnh Kon Tum), Kbang, Đức Cơ, Ia Grai, Chư Pưh (tỉnh Gia Lai), Đắk Mil, Krông Nô, Đắk RLấp (Đắk Nông), Krông Ana, Buôn Đôn, M'Đrắk, Krông Păk, IaKa (Đắk Lắk), ở mức rất thấp như tỉnh Lâm Đồng (trừ các huyện Đà Lạt, Di Linh), huyện Đăk Pơ và Ayunpa (tỉnh Gia Lai).

Chỉ số dễ bị tổn thương trước thiên tai hạn hán chênh lệch nhau không nhiều, các tỉnh Gia Lai, Đắk có chỉ số dễ bị tổn thươngcao nhất và tương đồng nhau đạt 0.45 , tỉnh Lâm Đồng có chỉ số dễ bị tổn thương thấp nhất đạt 0.39 .

Một số nơi có chỉ số tổn thương ở mức rất cao như thành phố Kon Tum tỉnh Kon Tum, huyện Krông Nô, ĐăkMil tỉnh Đắk Nông, huyện M'Đrắk, Buôn Đôn, Krong Ana, Krong Păk tỉnh Đắk Lắk, huyện Đức Cơ, IaGrai, Chư Pưh tỉnh Gia Lai. Những huyện có chỉ số về tính tổn thương ở mức rất thấp là Đăk Hà tỉnh Kon Tum, huyện Đăk Pơ, huyện Ayunpa, IaPa tỉnh Gia Lai, huyện Tuy Đức, Đăk Glong tỉnh Đắk Nông và các huyện Lạc Dương, Đam Rông, Đơn Dương, Bảo Lâm, Đạ Hoai, Đạ Tẻh, Cát Tiên của tỉnh Lâm Đồng.

Bảng 8. Trọng số các chỉ số và chi số thành phà̀n thuộc tiêu chí tính dễ bị tổn thương do thiên tai hạn hán

\begin{tabular}{clc}
\hline Tiêu chí & \multicolumn{1}{c}{ Chỉ số } & Trọng số \\
\hline & 3.1. Dân số & 0.338 \\
& 3.2 Sinh kế & 0.105 \\
1. Tính nhạy & 3.3 Cơ cấu kinh tế & 0.356 \\
0.65 & 3.4 Môi trường & 0.062 \\
& 3.5. Thông tin dư báo, cảnh báo & 0.059 \\
& 3.6 Hiện trạng tự nhiên & 0.08 \\
\hline & 4.1 Khả năng tự phục hồi & 0.148 \\
2. Khả năng & 4.2 Cơ sở hạ tầng & 0.335 \\
chống chịu & 4.3. Ngân sách & 0.179 \\
0.35 & 4.4 Hỗ trợ của chính quyền cho người dân & 0.201 \\
& khi có hạn hán & \\
& 4.5 Cơ cấu tự thích nghi của người dân & 0.137 \\
\hline
\end{tabular}




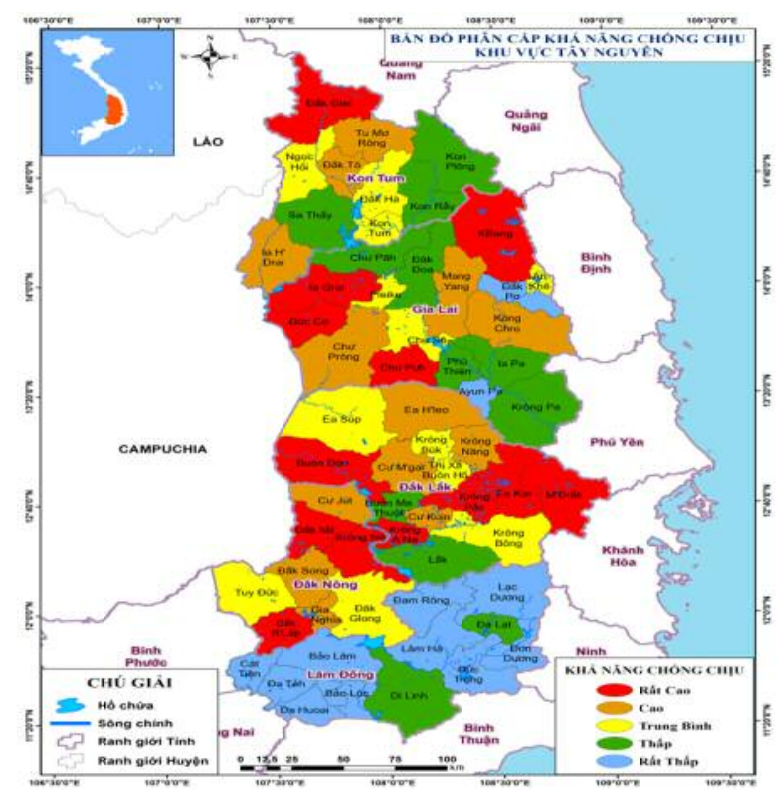

Hình 4. Bản đồ phân cấp khả năng ứng phó và chống chịu trước thiên tai hạn hán

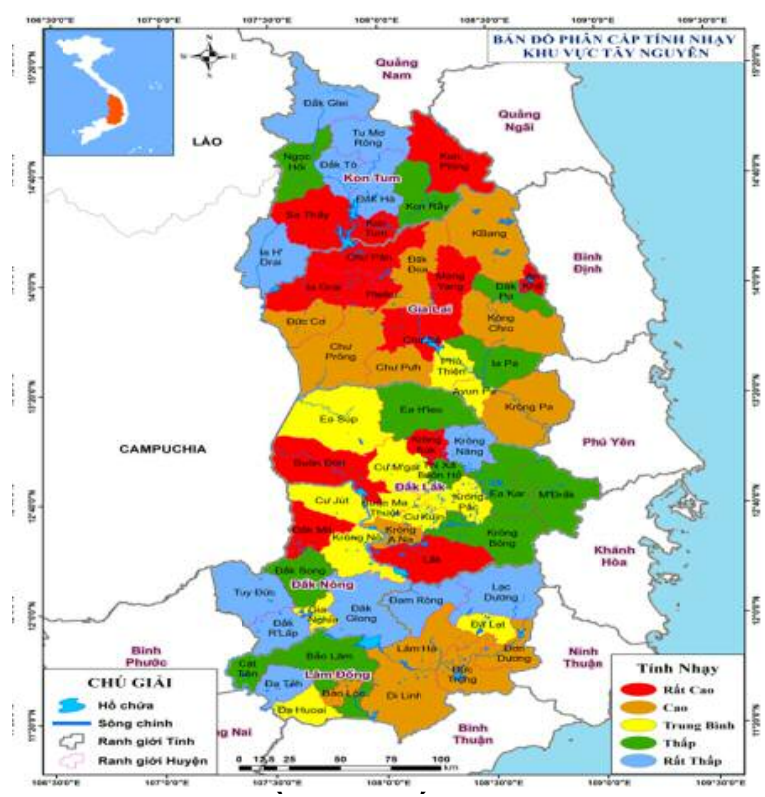

Hình 5. Bản đồ phân cấp tính nhạy truớc thiên tai hạn hán

Bảng 9. Chỉ số dễ bị tổn thương trung bình các tỉnh thuộc khu vực Tây Nguyên

\begin{tabular}{|c|c|c|c|c|c|c|c|}
\hline Tỉnh & $\begin{array}{c}\text { Dân số } \\
\text { (Người) }\end{array}$ & $\begin{array}{c}\text { Tỷ lệ } \\
\text { đóng góp } \\
\text { vào ngân } \\
\text { sách địa } \\
\text { phương } \\
\text { của } \\
\text { ngành } \\
\text { nông, } \\
\text { lâm } \\
\text { nghiệp } \\
\text { (\%) }\end{array}$ & $\begin{array}{c}\text { Tỷ lệ } \\
\text { đóng góp } \\
\text { vào ngân } \\
\text { sách địa } \\
\text { phương } \\
\text { của } \\
\text { ngành } \\
\text { công } \\
\text { nghiệp } \\
(\%)\end{array}$ & $\begin{array}{c}\text { Tỷ lệ } \\
\text { đóng góp } \\
\text { vào ngân } \\
\text { sách địa } \\
\text { phương } \\
\text { của } \\
\text { ngành } \\
\text { dịch vụ } \\
(\%)\end{array}$ & $\begin{array}{l}\text { Diện } \\
\text { tích đất } \\
\text { sản xuất } \\
\text { nông } \\
\text { nghiệp } \\
\text { (ha) }\end{array}$ & $\begin{array}{l}\text { Diện } \\
\text { tích đất } \\
\text { lâm } \\
\text { nghiệp } \\
\text { (ha) }\end{array}$ & $\begin{array}{l}\text { Chỉ số } \\
\text { dễ bị } \\
\text { tồn } \\
\text { thương }\end{array}$ \\
\hline Kon tum & 508,502 & 44.0 & 22.0 & 34.0 & 214,856 & 641,056 & 0.43 \\
\hline Gia Lai & $1,397,400$ & 38.0 & 27.7 & 34.3 & 801,727 & 588,648 & 0.45 \\
\hline Đắk Lắk & $1,874,459$ & 44.4 & 17.4 & 38.2 & 627,126 & 528,643 & 0.45 \\
\hline Đắk Nông & 609,595 & 40.0 & 33.6 & 26.4 & 360,153 & 235,556 & 0.44 \\
\hline Lâm Đồng & $1,270,014$ & 46.8 & 17.8 & 35.4 & 539,792 & 27,594 & 0.39 \\
\hline
\end{tabular}

* Số liệu điều tra đề tài TNMT.2017.05.21

Như vậy theo kết quả tính toán trên thì với nguy cơ tổn thương do hạn hán gây ra cho 5 tỉnh ở khu vực Tây Nguyên, tỉnh Gia Lai có số huyện có nguy cơ cao chiếm $65 \%$, số nguy cơ thấp chiếm $24 \%$ và $11 \%$ số huyện có nguy cơ trung bình; tỉnh Đắk Lắk có số huyện có nguy cơ cao chiếm $60 \%$, số nguy cơ thấp chiếm $7 \%$ và $33 \%$ số huyện có nguy cơ trung bình; tỉnh Đắk Nông có số huyện có nguy cơ cao chiếm $38 \%$, số nguy cơ thấp chiếm $25 \%$ và $37 \%$ số huyện có nguy cơ trung bình; tỉnh Kon Tum có số huyện có nguy cơ cao chiếm $30 \%$, số nguy cơ thấp chiếm $50 \%$ và $20 \%$ số huyện có nguy cơ trung bình; tỉnh Lâm Đồng có số huyện có nguy cơ cao chiếm $0 \%$, số nguy cơ thấp chiếm $92 \%$ và $8 \%$ số huyện có nguy cơ trung bình. 
BÀI BÁO KHOA HỌC

Bảng 10. Kết quả tính toán \% số huyện có tính dễ bị tổn thương do hạn hán theo các mức

\begin{tabular}{lccccc}
\hline Rủi ro & Rất cao & Cao & Trung bình & Thấp & Rất thấp \\
\hline Kon Tum & 10 & 20 & 20 & 40 & 10 \\
Gia Lai & 35 & 29 & 12 & 6 & 18 \\
Đắk Lắk & 27 & 33 & 33 & 7 & 0 \\
Đắk Nông & 25 & 13 & 38 & 0 & 25 \\
Lâm Đồng & & & 8 & 33 & 58 \\
\hline
\end{tabular}

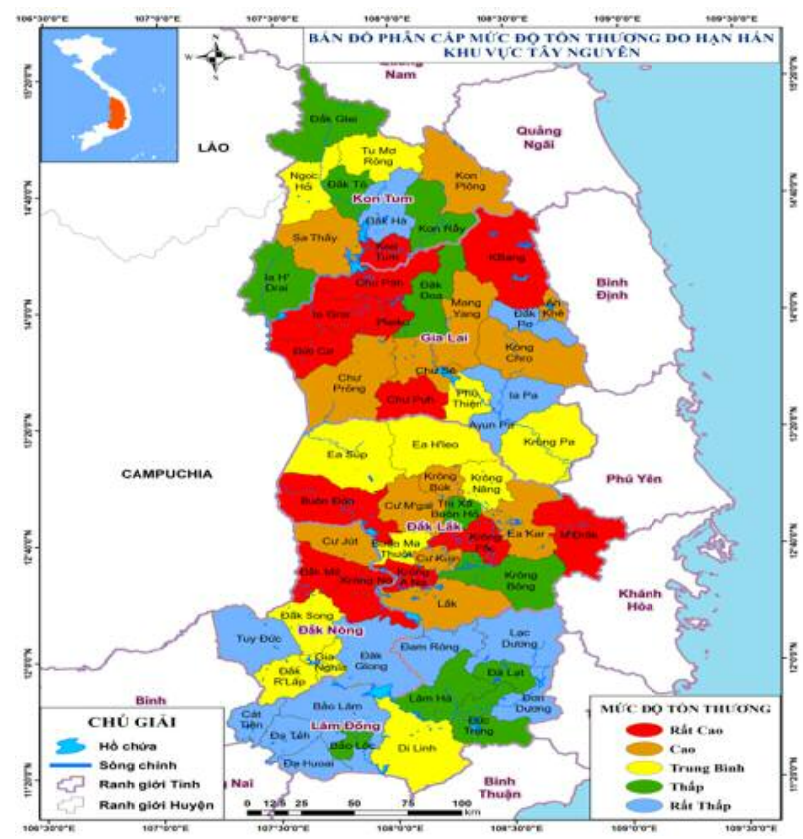

Hình 6. Bản đồ phân cấp tính dễ bị tổn thưong do thiên tai hạn hán khu vưc Tây Nguyên

\section{4. Đánh giá nguy co rủi ro}

Nguy cơ rủi ro do thiên tai hạn hán được xác định dựa trên việc tổng hợp 3 thành phần: nguy cơ hiểm họa, tính phơi bày và khả năng dễ bị tổn thương trước thiên tai. Kết quả tính toán và phân cấp nguy cơ rủi ro do hạn hán cho các huyện thuộc khu vực Tây Nguyên được trình bày trong bảng 11 .

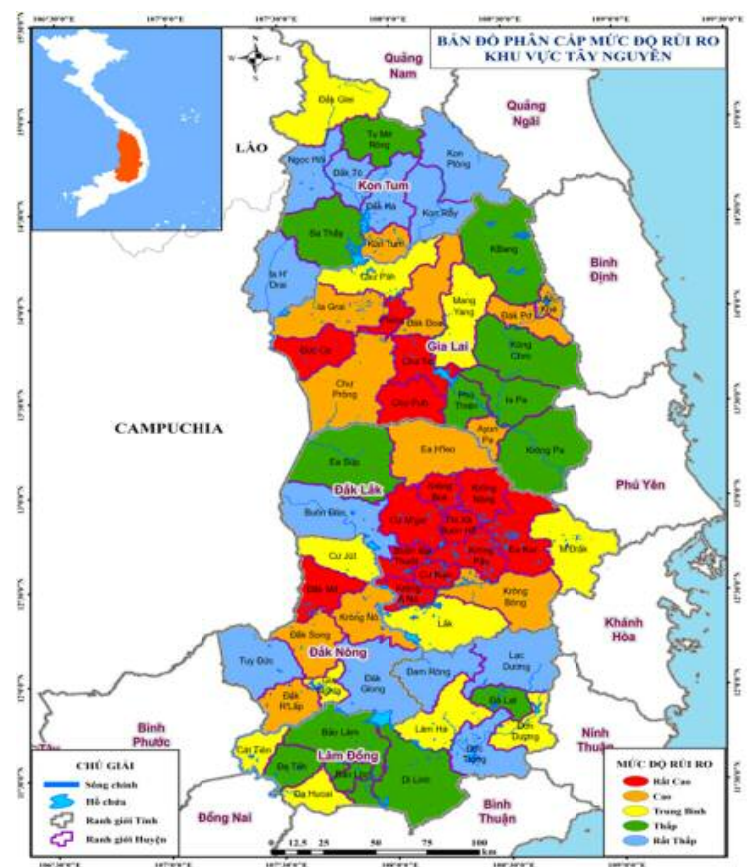

Hình 7. Bản đồ phân cấp nguy cơ rủi ro do thiên tai hạn hán khu vực Tây Nguyên 
Bảng 11. Phân cấp cấp độ rủi ro do hạn hán cho 5 tỉnh khu vục Tây Nguyên

\begin{tabular}{|c|c|c|c|c|c|c|}
\hline TT & Tỉnh & Huyện & Hiểm họa & $\begin{array}{l}\text { Mức độ phơi } \\
\text { bày }\end{array}$ & $\begin{array}{l}\text { Tính dễ bị } \\
\text { tồn thương }\end{array}$ & Rủi ro \\
\hline 1 & \multirow{10}{*}{ Kon Tum } & TP KonTum & Rất thấp & Rất cao & Rất cao & Cao \\
\hline 2 & & Ia H'Drai & Thấp & Thấp & Trung bình & Rất thấp \\
\hline 3 & & ĐăkTô & Rất thấp & Trung bình & Thấp & Rất thấp \\
\hline 4 & & Tu Mơ Rông & Thấp & Thấp & Trung bình & Thấp \\
\hline 5 & & KonPlong & Trung bình & Rất thấp & $\mathrm{CaO}$ & Rất thấp \\
\hline 6 & & Kon Rẫy & Rất thấp & Rất thấp & Thấp & Rất thấp \\
\hline 7 & & Sa Thầy & Rất cao & Rất thấp & $\mathrm{CaO}$ & Thấp \\
\hline 8 & & Đăk Glei & Rất cao & Rất thấp & Thấp & Trung bình \\
\hline 9 & & Đăk Hà & Rất thấp & Trung bình & Rất thấp & Rất thấp \\
\hline 10 & & Ngọc Hồi & Rất thấp & Thấp & Trung bình & Rất thấp \\
\hline 11 & \multirow{8}{*}{ Đắk Nông } & Đăk Mil & Trung bình & $\mathrm{Cao}$ & Rất cao & Rất cao \\
\hline 12 & & Đắk R'lấp & Trung bình & $\mathrm{Cao}$ & Trung bình & $\mathrm{Cao}$ \\
\hline 13 & & Đắk Glong & Trung bình & Rất thấp & Rất thấp & Rất thấp \\
\hline 14 & & Tuy Đức & Thấp & Thấp & Rất thấp & Rất thấp \\
\hline 15 & & Cư Jút & Trung bình & Trung bình & $\mathrm{CaO}$ & Trung bình \\
\hline 16 & & Đắk Song & $\mathrm{Cao}$ & Trung bình & Trung bình & Cao \\
\hline 17 & & Krông Nô & Trung bình & Trung bình & Rất cao & $\mathrm{Cao}$ \\
\hline 18 & & Gia Nghĩa & Thấp & Thấp & $\mathrm{Cao}$ & Trung bình \\
\hline 19 & \multirow{15}{*}{ Đắk Lắk } & Krông Năng & Rất cao & Rất cao & Trung bình & Rất cao \\
\hline 20 & & Cư Kuin & $\mathrm{Cao}$ & Rất cao & Cao & Rất cao \\
\hline 21 & & Buôn Đôn & Rất thấp & Rất thấp & Rát cao & Rất thấp \\
\hline 22 & & M'Đrắk & Trung bình & Thấp & Rất cao & Trung bình \\
\hline 23 & & EaKar & Rất cao & Trung bình & Cao & Rất cao \\
\hline 24 & & Krông Pắc & Rất cao & Rất cao & Rất cao & Rất cao \\
\hline 25 & & TX Buôn Hồ & Rất cao & Rất cao & Thấp & Rất cao \\
\hline 26 & & Ea H'leo & $\mathrm{Cao}$ & Trung bình & Trung bình & $\mathrm{CaO}$ \\
\hline 27 & & Krông Búk & Rất cao & Rất cao & Cao & Rất cao \\
\hline 28 & & Krông Bông & $\mathrm{Cao}$ & Thấp & Trung bình & $\mathrm{Cao}$ \\
\hline 29 & & Cư M'gar & Rất cao & Rất cao & Cao & Rất cao \\
\hline 30 & & Lắk & Rất cao & Rất thấp & Cao & Trung bình \\
\hline 31 & & $\begin{array}{l}\text { TP Buôn Ma } \\
\text { Thuột }\end{array}$ & Cao & Rất cao & Trung bình & Rất cao \\
\hline 32 & & Ea Súp & Rất cao & Rất thấp & Trung bình & Thấp \\
\hline 33 & & Krông Ana & Cao & $\mathrm{CaO}$ & Rất cao & Rất cao \\
\hline 34 & \multirow{8}{*}{ Lâm Đồng } & Đơn Dương & Thấp & Trung bình & Rất thấp & Trung bình \\
\hline 35 & & Đức Trọng & Rất thấp & $\mathrm{CaO}$ & Trung bình & Rất thấp \\
\hline 36 & & Đam Rông & Trung bình & Rất thấp & Rất thấp & Rất thấp \\
\hline 37 & & Di Linh & Rất thấp & Thấp & Trung bình & Thấp \\
\hline 38 & & Lâm Hà & Thấp & $\mathrm{CaO}$ & Thấp & Trung bình \\
\hline 39 & & Bảo Lâm & $\mathrm{CaO}$ & Thấp & Rất thấp & Thấp \\
\hline 40 & & Đạ Hoai & $\mathrm{Cao}$ & Thấp & Rất thấp & Trung bình \\
\hline 41 & & Đà Lạt & Rất thấp & Rất cao & Trung bình & Thấp \\
\hline 42 & & Lạc Dương & $\mathrm{Cao}$ & Rất thấp & Rất thấp & Rất thấp \\
\hline 43 & & Cát Tiên & $\mathrm{Cao}$ & Trung bình & Rất thấp & Trung bình \\
\hline 44 & & Đạ Tẻh & $\mathrm{Cao}$ & Rất thấp & Rất thấp & Thấp \\
\hline 45 & & TP. Bảo Lôc & Rất thấp & Rất cao & Thấp & Thấp \\
\hline
\end{tabular}


BÀI BÁO KHOA HỌC

\begin{tabular}{|c|c|c|c|c|c|c|}
\hline TT & Tỉnh & Huyện & Hiểm họa & $\begin{array}{l}\text { Mức độ phơi } \\
\text { bày }\end{array}$ & $\begin{array}{l}\text { Tính dễ bị } \\
\text { tổn thương }\end{array}$ & Rủi ro \\
\hline 46 & & ĐăkPơ & Rất caó & Trung binh & Rât thâp & Cao \\
\hline 47 & & IaGrai & Trung bình & Cao & Rất cao & Cao \\
\hline 48 & & Đức Cơ & Trung bình & $\mathrm{Cao}$ & Rất cao & Rất cao \\
\hline 49 & & Mang Yang & Trung bình & Trung bình & Cao & Trung bình \\
\hline 50 & & Chư Pưh & Rất cao & Rất cao & Rất cao & Rất cao \\
\hline 51 & & Kông Chro & Thấp & Thấp & Cao & Thấp \\
\hline 52 & & ChưPrông & Cao & Trung bình & Cao & Cao \\
\hline 53 & & KBang & Thấp & Rất thấp & Rất cao & Thấp \\
\hline 54 & Gia Lai & Chư Păh & Rất thấp & Cao & Rất cao & Trung bình \\
\hline 55 & & Phú Thiện & Rất thấp & $\mathrm{Cao}$ & Trung bình & Thấp \\
\hline 56 & & Ayun $\mathrm{Pa}$ & Cao & Trung bình & Rất thấp & $\mathrm{Cao}$ \\
\hline 57 & & Krông Pa & Thấp & Thấp & Trung bình & Thấp \\
\hline 58 & & Iapa & Thấp & Thấp & Rất thấp & Thấp \\
\hline 59 & & Chư sê & Rất cao & Trung bình & Cao & Rất cao \\
\hline 60 & & Đăk Đoa & Сao & Rât cao & Trung bình & Сao \\
\hline 61 & & PlêiKu & Thấp & Rât cao & Rât cao & Rât cao \\
\hline 62 & & TX An Khê & Trung bình & Rất cao & $\mathrm{CaO}$ & $\mathrm{CaO}$ \\
\hline
\end{tabular}

Bảng 12. Tổng hợp các chỉ số rủi ro 5 tỉnh khu vực Tây Nguyên

\begin{tabular}{lcccc}
\hline \multicolumn{1}{c}{ Tỉnh } & Chỉ số hiểm họa & $\begin{array}{c}\text { Chỉ số phơi } \\
\text { bày }\end{array}$ & $\begin{array}{c}\text { Chỉ số dễ bị tổn } \\
\text { thương }\end{array}$ & Chỉ số rủi ro \\
\hline Kon tum & 0.34 & 0.301 & 0.43 & 0.039 \\
Gia Lai & 0.40 & 0.407 & 0.45 & 0.076 \\
Đắk Lắk & 0.50 & 0.422 & 0.45 & 0.097 \\
Đắk Nông & 0.35 & 0.359 & 0.44 & 0.064 \\
Lâm Đồng & 0.42 & 0.365 & 0.39 & 0.043 \\
\hline
\end{tabular}

Đánh giá rủi ro do thiên tai hạn hán cho từng tỉnh thuộc khu vực Tây Nguyên qua các kết quả tính toán và thống kê cho thấy:

- Đắk Lắk có nền nông nghiệp đóng vai trò chủ đạo trong cơ cấu kinh tế (tỷ lệ đóng góp vào ngân sách địa phương của ngành nông, lâm nghiệp khoảng 44.4\%). Tỷ trọng ngành nông nghiệp trong cơ cấu tổng sản phẩm của Đắk Lắk cao tương đương Kon Tum. Trong khi đó nông nghiệp là ngành phụ thuộc vào điều kiện tự nhiên và chịu ảnh hưởng rất nghiêm trọng từ hạn hán. Mặt khác, tổng sản phẩm nông nghiệp trên địa bàn của Đắk Lắk vào loại cao nhất trong vùng. Điều này càng cho thấy sự phụ thuộc của nền kinh tế tỉnh vào ngành nông nghiệp. Nếu ngành nông nghiệp chịu thiệt hại nặng nề của hạn hán sẽ dẫn đến sự suy giảm mạnh mẽ của tổng sản phẩm trên địa bàn tỉnh. Nền kinh tế tỉnh trong tình trạng đó khó có thể phát triển một cách bền vững và ổn định. Tỷ lệ đóng góp vào ngân sách địa phương của ngành dịch vụ của Đắk Lắk cao nhất trong khu vực chiếm $38.2 \%$, chủ yếu là dịch vụ du lịch. Trong khi tỷ lệ đóng góp vào ngân sách địa phương của ngành công nghiệp chiếm tỷ lệ thấp nhất trong khu vực $17.4 \%$. Tỉnh Đắk Lắk có các chỉ số hiểm họa, mức độ phơi bày và tính dễ bị tổn thương cao nhất trong vùng đồng thời cũng có chỉ số rủi ro cao nhất trong vùng.

- Gia Lai là tỉnh có cơ cấu kinh tế tương đối cân đối hơn các tỉnh khác, ngành nông nghiệp đóng vai trò quan trọng nhất chiếm $38 \%$ và là tỷ lệ thấp nhất trong khu vực, chênh lệch với tỷ lệ đóng góp của ngành dịch vụ không cao chỉ 4\% trong khi tỷ lệ đóng góp của ngành công nghiệp là $27 \%$. Gia Lai là tỉnh có diện tích đất nông nghiệp lớn nhất trong 5 tỉnh và diện tích đất rừng lớn thứ 2 trong vùng. Gia Lai là một trong hai tỉnh có chỉ số dễ bị tổn thương cao nhất trong vùng, tính phơi bày cao thứ hai trong vùng, nguy cơ hiểm họa cao thứ ba và có chỉ số rủi ro cao thứ hai trong vùng.

- Đắk Nông cũng là tỉnh có nền kinh tế nông 
nghiệp với số lao động nông nghiệp chiếm tỉ lệ rất cao trong tổng số lao động. Tỷ lệ đóng góp vào ngân sách địa phương của ngành nông, lâm nghiệp cũng tương đối cao, đạt 40\%. Tuy nhiên, tỉnh có diện tích cây lúa vào loại thấp nhất trong 5 tỉnh của vùng Tây Nguyên. Theo kết quả tính toán, diện tích cây lúa ở Đắk Nông chỉ chiếm $15 \%$ tổng diện tích cây trồng. Đắk Nông là tỉnh có diện tích sản xuất nông nghiệp thấp thứ 2 trong vùng, sau Kon Tum. Tỷ lệ đóng góp vào ngân sách địa phương của ngành công nghiệp khá cao đạt $33.6 \%$, ngành dịch vụ chiếm $24.6 \%$ đều ở mức tương đối đồng đều. Chỉ số dễ bị tổn thương của Đắk Nông cao thứ ba trong vùng và chỉ số rủi ro cao thứ 3 trong vùng.

- Lâm Đồng có nền kinh tế chịu ảnh hưởng nhiều của nông nghiệp và dịch vụ. Tỷ lệ đóng góp vào ngân sách địa phương của ngành nông, lâm nghiệp đạt 46,8\%. Lao động nông nghiệp chiếm 73,21\% trong tổng số lao động đang hoạt động trong các ngành kinh tế. Cây lúa có diện tích chiếm trên $55 \%$ diện tích cây trồng của tỉnh. Đây là cây trồng có diện tích lớn thứ hai của tỉnh, sau cây cà phê. Lâm Đồng cũng là tỉnh có diện tích cây lúa chiếm tỉ lệ lớn nhất trong tổng diện tích cây trồng trong số 5 tỉnh vùng Tây Nguyên. Ngoài ra, tỷ lệ đóng góp vào ngân sách địa phương của ngành dịch vụ đạt $35,4 \%$ cao thứ 2 sau Đắk Lắk, tỷ lệ đóng góp vào ngân sách địa phương của ngành công nghiệp đạt 17.8\%. Lâm Đồng là tỉnh có chỉ số dễ bị tổn thương thấp nhất trong khu vực nhưng lại có chỉ số nguy cơ hiểm họa do hạn hán cao thứ hai và là tỉnh có chỉ số rủi ro đứng thứ tư trong khu vực.

- Cơ cấu kinh tế tại Kon Tum tương đối cân đối, ngành nông nghiệp đóng vai trò quan trọng nhất chiếm 44\%. Số lao động trong nông nghiệp của Kon Tum chiếm tỉ lệ rất lớn trong tổng số lao động hoạt động của các ngành kinh tế. Cây lúa giữ một vai trò thiết yếu trong cơ cấu cây trồng tại Kon Tum, nhưng không phải là cây trồng độc canh của tỉnh. Kon Tum còn có nhiều loại cây công nghiệp hàng năm và lâu năm và có đóng góp lớn cho giá trị sản xuất nông nghiệp của tỉnh. Diện tích đất sản xuất nông nghiệp của Kon Tum thuộc loại thấp nhất trong khi diện tích đất lâm nghiệp thuộc loại cao nhất trong vùng. Tỷ lệ đóng góp vào ngân sách địa phương của ngành công nghiệp đạt $22 \%$ Tỷ lệ đóng góp vào ngân sách địa phương của ngành dịch vụ đạt 34\%. Chỉ số dễ bị tổn thương của Kon Tum cao thứ 4 trong vùng, chỉ số phơi bày thấp nhất và chỉ số rủi ro đứng thấp nhất trong khu vực.

Như vậy, có 44\% số huyện ở khu vực Tây Nguyên có mức độ rủi ro được quyết định bởi thành phần hiểm họa, có 37\% số huyện có mức độ rủi ro được quyết định bởi thành phần mức độ phơi bày và $19 \%$ số huyện có mức độ rủi ro được quyết định bởi thành phần tính dễ bị tổn thương.

Số huyện có nguy cơ rủi ro do hạn hán ở các cấp độ khác nhau cũng khác nhau. Tỉnh Đắk Lắk có số huyện có nguy cơ cao đến rất cao chiếm $73 \%$ và $13 \%$ số huyện có nguy cơ trung bình, 14\% số huyện có mức độ rủi ro ở mức thấp; tỉnh Gia Lai có số huyện có nguy cơ cao đến rất cao chiếm $59 \%$, số nguy cơ thấp chiếm $29 \%$ và $12 \%$ số huyện có nguy cơ trung bình; tỉnh Đắk Nông có số huyện có nguy cơ cao đến rất cao chiếm $51 \%$, số nguy cơ thấp chiếm $25 \%$ và $25 \%$ số huyện có nguy cơ trung bình; tỉnh Kon Tum có số huyện có nguy cơ cao đến rất cao chiếm $10 \%$, số nguy cơ thấp $80 \%$ và $10 \%$ số huyện có nguy cơ trung bình; tỉnh Lâm Đồng không có huyện nào ở mức nguy cơ cao, số nguy cơ thấp và rất thấp chiếm $67 \%$ và $33 \%$ số huyện có nguy cơ trung bình.

Bảng 13. Kết quả tính toán \% số huyện có nguy co rủi ro do hạn hán theo các mức

\begin{tabular}{lccccc}
\hline Rủi ro & Rất cao & Cao & Trung bình & Thấp & Rất thấp \\
\hline Kon Tum & & 10 & 10 & 20 & 60 \\
Gia Lai & 24 & 35 & 12 & 29 & \\
Đắk Lắk & 60 & 13 & 13 & 7 & 7 \\
Đắk Nông & 13 & 38 & 25 & & 25 \\
Lâm Đồng & & & 33 & 42 & 25 \\
\hline
\end{tabular}




\section{Kết luận}

Hạn hán là thiên tai khắc nghiệt xảy ra ở Tây Nguyên hàng năm và ảnh hưởng tới các hoạt động kinh tế - xã hội của vùng với quy mô, mức độ và phạm vi khác nhau theo từng tỉnh. Bài báo sử dụng phương pháp của IPCC, coi rủi ro là tổng hợp của 3 thành phần nguy cơ hiểm họa, tính phơi bày và tính dễ bị tổn thương.

Để đánh giá nguy cơ hiểm họa do hạn hán gây ra, bài báo dựa trên các tiêu chí thiếu hụt mưa và thiếu hụt dòng chảy. Các chỉ tiêu để đánh giá thiếu hụt mưa và dòng chảy dựa trên Quyết định 44/2014/QĐ-TTg của Thủ tướng Chính phủ quy định chi tiết về dự báo, cảnh báo và truyền tin thiên tai cho hạn hán. Mức độ phơi bày trước hiểm họa do hạn hán gây ra thể hiện qua các tiêu chí về sử dụng đất và mật độ dân số trong vùng chịu ảnh hưởng bởi hạn hán. Tính dễ bị tổn thương bao gồm sự nhạy cảm và khả năng chống chịu của mỗi khu vực khi thiên tai khi xảy ra. Các tiêu chí đánh giá tính nhạy trước hiểm họa do hạn hán bao gồm: Thông tin về dân số, sinh kế, thông tin về cảnh báo dự báo, môi trường, hiện trạng tự nhiên của rừng và nước ngầm trong khu vực xảy ra hạn hán; Khả năng chống chịu sử dụng các tiêu chí: Khả năng tự phục hôi, cơ sở hạ tâng, ngân sách, hỗ trợ của chính quyền cho người dân khi có hạn hán, tự thích nghi của dân.

Kết quả tính toán cho thấy Đắk Lắk là tỉnh có số huyện có nguy cơ rủi ro do hạn hán cao nhất chiếm $73 \%$, tiếp theo là Gia Lai chiếm $59 \%$, Kon Tum có nguy cơ rủi ro thấp nhất với $80 \%$ số huyện có nguy cơ rủi ro ở mức thấp. Thành phần hiểm họa có vai trò tương đối cao trong đánh giá rủi ro do hạn hán cho khu vực Tây Nguyên với 44\% số huyện có mức độ rủi ro được quyết định bởi thành phần này, tiếp theo là mức độ phơi bày quyết định mức độ rủi ro cho $37 \%$ số huyện và $19 \%$ số huyện do thành phần tính dễ bị tổn thương quyết định mức độ rủi ro.

Bài báo chỉ giới hạn phạm vi nghiên cứu lãnh thổ là khu vực Tây Nguyên, chính vì vậy nguồn số liệu chỉ so sánh trong phạm vi vùng. Kết quả nghiên cứu có thể sử dụng trong công tác quy hoạch, định hướng phát triển kinh tế - xã hội ở khu vực Tây Nguyên và phục vụ công tác cảnh báo cấp độ rủi ro do hạn hán tại Quyết định số 44/2014/QĐ-TTg ngày 15 tháng 8 năm 2014 của Thủ tướng Chính phủ.

Lời cảm ơn: Các nội dung nghiên cưu trên nằm trong khuôn khổ của đề tài "Nghiên cứu co" sở khoa học và thực tiễn phục vu cảnh báo cấp độ rủi ro thiên tai do hạn hán cho các địa phưong thuộc khu vực Tây Nguyên trong điều kiện biến đổi khi hậu”, Mã số TNMT.2017.05.21.

\section{Tài liệu tham khảo}

1. Quyết định 44/2014/QĐ-TTg ngày 15 tháng 8 năm 2014 của Thủ tướng Chính phủ quy định chi tiết về dự báo, cảnh báo và truyền tin thiên tai.

2. SREX (2015), Báo cáo đặc biệt của Việt Nam về quản lý rủi ro thiên tai và các hiện tượng cực đoan nhằm thúc đẩy thích ứng với biến đổi khí hậu, Nhà xuất bản Tài nguyên - Môi trường và Bản đồ Việt Nam.

3. GIZ and EURAC (2017), Risk Supplement to the Vulnerability Sourcebook. Guidance on how to apply the Vulnerability Sourcebook's approach with the new IPCC AR5 concept of climate risk. Bonn: GIZ.

4. IPCC (2012), Managing the Risks of Extreme Events and Disasters to Advance Climate Change Adaptation, Special Report of the Intergovernmental Panel on Climate Change, Cambridge University Press. 


\title{
ASSESSING THE DROUGHT RISK SERVING SOCIO-ECONOMIC DE- VELOPMENT FOR THE CENTRAL HIGHLAND REGION
}

\author{
Vu Duc Long ${ }^{1}$, Nguyen Thi Thu Trang ${ }^{2}$ \\ ${ }^{1}$ National Center for Hydro-Meteorological Forecasting \\ ${ }^{2}$ Department of Meteorological and Hydrological Forecasting Management
}

\begin{abstract}
The research paper assesses the level of risk caused by drought natural disasters for the Central Highlands region using the IPCC method, considering the risk as a combination of 3 risk components, exposure and vulnerability. The calculated results show that $44 \%$ of the districts in the Central Highlands region have a level of risk decided by the hazard component, 37\% of the districts have a level of risk decided by the component. The level of exposure and 19\% of the districts where the level of risk is determined by the vulnerability composition. Dak Lak is the province with the highest risk of drought due to drought, accounting for 73\%, followed by Kon Tum with 59\%, Kon Tum with the lowest risk with $80 \%$ of the districts at risk. low. The results are presented on risk zoning maps with levels from very low to low, medium, high and can be used in the planning and socioeconomic development orientations in the Central Highlands region and for alerting the drought risk level in Decision No. 44/2014 / QD-TTg August 15, 2014 of the Prime Minister.
\end{abstract}

Keywords: Risk, drought, Central Highland. 